\title{
Differential expression of key pneumococcal virulence genes in vivo
}

\author{
Kim S. LeMessurier, Abiodun David Ogunniyi and James C. Paton \\ School of Molecular and Biomedical Science, The University of Adelaide, Adelaide, \\ South Australia 5005, Australia
}

Correspondence

James C. Paton

james.paton@adelaide.edu.au

Received 12 August 2005

Revised 10 October 2005

Accepted 11 October 2005

\begin{abstract}
Few studies have examined in vivo virulence gene expression in Streptococcus pneumoniae. In this study, expression of key pneumococcal virulence genes $c b p A, p s p A, p l y, p s a A, c p s 2 A$, piaA, nan $A$ and $s p \times B$ in the nasopharynx, lungs and bloodstream of mice was investigated, following intranasal challenge with the serotype 2 strain D39. Bacterial RNA was extracted, linearly amplified and assayed by real-time RT-PCR. At 72 h, cbpA mRNA was present at higher levels in the nasopharynx and lungs than in the blood. At this time-point, the mRNAs for PspA and PiaA were most abundant in the nasopharynx, whereas no significant difference in gene expression between niches was observed for $p l y, p s a A$ and $\operatorname{cps} 2 A$. Both nan $A$ and $s p x B$ mRNAs were present in higher amounts in the nasopharynx than in the lungs or blood. These findings illustrate the dynamic nature of pneumococcal virulence gene expression in vivo.
\end{abstract}

\section{INTRODUCTION}

Streptococcus pneumoniae (the pneumococcus) is a globally significant pathogen, responsible for invasive diseases such as pneumonia, bacteraemia and meningitis (Paton, 1998). The pneumococcus asymptomatically colonizes the nasopharynx, and such carriage is considered essential for subsequent development of disease in susceptible individuals (particularly infants, the elderly, and the immunocompromised). Disease commonly occurs following the aspiration of bacteria from the nasopharynx into the lungs, followed by colonization of the pulmonary epithelium and subsequent development of pneumonia. From this niche, the pneumococcus can invade the bloodstream and cause sepsis. Alternatively, bacteraemia can occur, following direct translocation from the nasopharyngeal epithelium into underlying tissues. The gene regulatory mechanisms involved in transition between, and survival in, these distinct host niches are poorly understood. This has primarily been due to technical difficulties in harvesting sufficient quantities of pneumococci from an animal model to perform accurate and quantitative RNA assays, particularly from niches such as the nasopharynx, in which bacteria exist asymptomatically and in low numbers.

Several studies have been conducted in recent years comparing in vivo and in vitro pneumococcal gene expression. Orihuela et al. (2000) used Northern blotting to assess virulence gene mRNA levels in type 3 pneumococci grown in sealed dialysis bags implanted in the murine peritoneal cavity. In another study, differences in gene expression between virulent type 2 pneumococci harvested from the blood of mice infected intraperitoneally and those grown in serum broth were examined using semi-quantitative
RT-PCR (Ogunniyi et al., 2002). More recently, in vivo studies have used microarray technology to quantitate $S$. pneumoniae transcript abundance in the blood of infected mice and the cerebrospinal fluid of infected rabbits (Orihuela et al., 2004b).

The present work is the first to evaluate in vivo changes in pneumococcal gene expression during the natural progression of disease from colonization of the nasopharynx to invasion of the lungs and blood. We examined the mRNA expression of genes encoding eight virulence factors considered important in promoting carriage or disease: the choline-binding proteins $c b p A$ and $p s p A$, the pneumococcal cytotoxin pneumolysin ( $p l y)$, the first gene of the capsular polysaccharide biosynthesis locus ( $\operatorname{cps} 2 A)$, one of the three known pneumococcal neuraminidases (nanA), ion transporters ( $p s a A$ and $p i a A)$, and pyruvate oxidase $(s p x B)$.

\section{METHODS}

Challenge of mice and harvesting of pneumococci. Outbred 5- to 6-week-old female CD-1 mice (obtained from the Institute of Medical and Veterinary Science, Adelaide, South Australia) were intranasally infected with the type 2 pneumococcal strain D39 (Avery et al., 1944). Two separate experiments were performed, as follows. Before infection, bacteria were grown statically at $37^{\circ} \mathrm{C}$ in Todd-Hewitt broth supplemented with $0.5 \%$ yeast extract (THY broth) to $\mathrm{OD}_{600} 0 \cdot 25$ (equivalent to approximately $1 \times 10^{8}$ c.f.u. $\mathrm{ml}^{-1}$ ). Mice were anaesthetized by intraperitoneal injection of Nembutal (pentobarbitone sodium, Rhone-Merieux) at a dose of 66 micrograms per gram body-weight, and challenged intranasally with approximately $10^{7}$ bacteria suspended in PBS. The challenge dose was confirmed by serial dilution and plating of the inocula on blood agar. Previously, we had established that mice infected intranasally with $1-2 \times 10^{7}$ c.f.u. of D39 usually succumb rapidly to the infection $>72 \mathrm{~h}$ after challenge (unpublished results). 
Therefore, $72 \mathrm{~h}$ was chosen as the end-point of infection in this work, in order to maximize the number of pneumococci recovered from the tissues. At this time-point, eight mice were sacrificed by $\mathrm{CO}_{2}$ asphyxiation, and nasopharyngeal washes, and lung and blood samples were collected using an adaptation of the protocol described by $\mathrm{Wu}$ et al. (1997). Briefly, the nasopharynx of each mouse was washed with $1 \mathrm{ml} 0.5 \%$ trypsin solution in PBS, and the washings were placed on ice until further use. Before perfusion, a sample of blood was recovered from the heart and placed on ice until further use. Mice were subsequently perfused with sterile PBS to remove blood-borne bacteria from the lungs. Lungs were removed and homogenized on ice in $2 \mathrm{ml}$ sterile PBS using a tissue homogenizer (Cat X120, Germany). To separate pneumococci from host cells, lung homogenates and blood samples were centrifuged at $855 \mathrm{~g}$ for $6 \mathrm{~min}$ at $4{ }^{\circ} \mathrm{C}$, as described previously (Ogunniyi et al., 2002). Nasopharyngeal washes, and lung and blood supernatants were subsequently centrifuged at $15500 \mathrm{~g}$ for $2 \mathrm{~min}$ at $4{ }^{\circ} \mathrm{C}$, and the bacterial pellet was stored at $-80^{\circ} \mathrm{C}$ until further processing. Prior to pelleting harvested bacteria, $40 \mu \mathrm{l}$ was removed, serially diluted in PBS and plated onto blood agar in order to enumerate pneumococci present in the sample, and to determine the presence, if any, of contaminating microflora. Blood plates were incubated at $37^{\circ} \mathrm{C}$ in $95 \%$ air $/ 5 \%$ $\mathrm{CO}_{2}$ overnight.

Extraction of RNA from bacteria. RNA was isolated from bacterial pellets with acid-phenol/chloroform/isoamyl alcohol (125:24:1, $\mathrm{pH} 4.5$; Ambion, catalogue no. 9722) essentially as described previously (Ogunniyi et al., 2002). The extract was then precipitated at $-80{ }^{\circ} \mathrm{C}$ overnight in the presence of $40 \mathrm{ng}$ glycogen $\mu \mathrm{l}^{-1}$ (Sigma 1767). Subsequently, the preparation was treated with $10 \mathrm{U}$ RNasefree DNase (Roche) at $37^{\circ} \mathrm{C}$ for $30 \mathrm{~min}$ in the presence of $1 \mathrm{U} \mu \mathrm{l}^{-1}$ recombinant RNasin ribonuclease inhibitor (Promega N251A), after which RQ1 DNase stop buffer (Promega M198A) was added to inactivate the DNase. The purity of the RNA preparation was confirmed by one-step RT-PCR with or without reverse transcriptase, using $16 \mathrm{~S}$ rRNA-specific primers, and the products were visualized after electrophoresis on a $2 \%$ TBE/agarose gel. In all cases, a PCR product was only seen in the presence of reverse transcriptase. RNA samples from a specific niche from four to five mice were pooled, based on the number of c.f.u. recovered (extracts of samples with low bacterial counts were not included) and also on the absence of contaminating bacteria, and then purified further using a Qiagen RNeasy minikit. RNA obtained from lung homogenates was further enriched for prokaryotic RNA using the MICROBEnrich kit (Ambion). The amount of RNA recovered following purification/ enrichment was determined by $\mathrm{OD}_{260 / 280}$ measurements.

Linear amplification of mRNA. Previously, in vivo RNA studies for bacteria such as $S$. pneumoniae have been restricted by the amount of bacteria harvested from the animal, and therefore the yield of RNA obtained. This problem was circumvented by using a novel, advanced, RNA linear amplification kit, SenseAMP Plus (Genisphere), which employs terminal transferase to synthesize a poly-T tail onto prokaryotic cDNA. Linear amplification is then driven by a T7 phage promoter, which is incorporated at the end of a synthetic poly-A primer. A second round of amplification was performed for all nasopharyngeal samples in order to obtain sufficient quantities of RNA for analysis by real-time RT-PCR. To determine the integrity of the second-round amplification, primary and secondary amplified RNA samples were compared using real-time RT-PCR. Analysis of the data obtained indicated a high correlation coefficient, and no significant difference was obtained between the amplifications, when subjected to Student's $t$ test (data not shown)

\section{RESULTS}

Until recently, evidence for expression of virulence factors of pneumococci has been largely limited to indirect serological studies. In this work, we examined in vivo changes in pneumococcal gene expression during the natural progression of disease from colonization of the nasopharynx to systemic disease in outbred CD-1 mice. Three niches were examined in this study: the nasopharynx, the lungs and the blood. At $72 \mathrm{~h}$ post-infection, the mean c.f.u. of pneumococci harvested from the nasopharynx was approximately $6 \times 10^{4}$ per mouse; in the lungs, the mean c.f.u. was $1 \times 10^{6}$, whereas approximately $2 \times 10^{7}$ c.f.u. $\mathrm{ml}^{-1}$ bacteria was recovered from the blood. These values were consistent between the two experiments.

\section{Differential expression of pneumococcal virulence genes in vivo}

We examined the differential expression of the characterized virulence genes $c b p A, p s p A, p l y, p s a A, c p s 2 A$, piaA, nan $A$ and $s p \times B$. The abundance of each mRNA present in amplified RNA recovered from nasopharyngeal, lung and blood-borne pneumococci was quantified by real-time RT-PCR. Genespecific LUX fluorogenic primer sets labelled with JOE were designed using the Invitrogen primer designer software, employing primers specific for $16 \mathrm{~S}$ rRNA as an internal control (Table 1). Primer-pair efficiency was analysed using varying concentrations of in vitro-derived template, and the CT values obtained corresponded to the expected relative concentrations of template. The optimal concentrations of primers used in these studies were determined empirically in accordance with the manufacturer's instructions. For relative quantification, total RNA for 16S rRNA quantification was diluted 1/400 before real-time RT-PCR, whereas for mRNA quantification, total RNA was tested neat. Real-time RT-PCR was performed on a Rotorgene RG-2000 thermocycler (Corbett Research, Mortlake, NSW, Australia) using the Superscript III One-Step RT-PCR system (Invitrogen), according to the manufacturer's instructions. Quantitative fold differences for each transcript were determined using the $2^{-\Delta \Delta C T}$ method described by Livak \& Schmittgen (2001). Amplification data for each gene were then compared to that obtained for the $16 \mathrm{~S}$ rRNA control, and presented as a relative fold increase/decrease between niches (Table 2). Data for each independent experiment were analysed relative to the level of the respective transcript in S. pneumoniae D39 grown in THY broth to $\mathrm{OD}_{600} 0 \cdot 25$ (Fig. 1).

The trends in gene expression for $c b p A, p s p A, c p s 2 A$, piaA, ply, nan $A$ and $s p x B$ were consistent at $72 \mathrm{~h}$ post-challenge between the two replicate experiments. The $\operatorname{cbp} A$ mRNA was detected at the highest levels in bacteria recovered from the nasopharynx and lungs, and at lower levels in bacteria from the blood. Similarly, the level of $p s p A$ mRNA was highest in bacteria harvested from the nasopharynx and blood, with lower levels detected from pneumococci recovered from the lungs. In contrast, $c p s 2 A$ was expressed at a relatively 
Table 1. Oligonucleotides used in this study

\begin{tabular}{|c|c|c|}
\hline Primer & Sequence $\left(5^{\prime} \rightarrow 3^{\prime}\right)$ & R6 annotation ${ }^{\star}$ \\
\hline $16 \mathrm{~S} F(\mathrm{JOE})$ & CAACATCACCGCATAAGAGTGGATG(JOE)TG & sprr01 \\
\hline $16 \mathrm{~S} \mathrm{R}$ & CAACGCAGGTCCATCTGGTA & \\
\hline $\operatorname{cbp} A \mathrm{~F}(\mathrm{JOE})$ & GATCGTTTGGTTGGGTAGTTACGACGA(JOE)C & spr1995 \\
\hline $\operatorname{cbp} A \mathrm{R}$ & GCAGAAGCTAAGAAGAAGGTTGAA & \\
\hline pspA F (JOE) & CTAGCGAACTGAGGAGAAAGCCGCGC(JOE)AG & spr0121 \\
\hline $\operatorname{psp} A \mathrm{R}$ & GGCTAGATACGCTTGTTGAACTGC & \\
\hline ply F (JOE) & CAACGAAGGATAGAGGCGACTGTCG(JOE)TG & spr1739 \\
\hline ply $\mathrm{R}$ & GAAAGAAAGAAGCGGAGCTTG & \\
\hline psaA F & GAACCACTTCCTGAAGACGTTAAG & spr1494 \\
\hline psaA R (JOE) & GAAACACAAFCATTGCCACCTGT(JOE)TC & \\
\hline $\operatorname{cps} 2 A \mathrm{~F}(\mathrm{JOE})$ & CAACTCGCGGGCATTTATGGAG(JOE)TG & spr0314 \\
\hline $\operatorname{cps} 2 A \mathrm{R}$ & GAAGTGAAGTTCAATCGCACATAG & \\
\hline piaA F (JOE) & CAGCACAAGCAAATTACGGTGTAAGTGC(JOE)G & spr0934 \\
\hline piaA R & TCGTCAAATAGGTTAGCTTTACCA & \\
\hline nanA F (JOE) & GACGTTGAGCAGTGGTATTTGGAACG(JOE)C & spr1536 \\
\hline $\operatorname{nan} A \mathrm{R}$ & CCGAAAGTTGAGTTTCATTTGC & \\
\hline $\operatorname{spxB} \mathrm{F}(\mathrm{JOE})$ & CACCGGCGACTCACTTGATTAACGG(JOE)G & spr0642 \\
\hline $\operatorname{spxB} \mathrm{R}$ & TTAACTGGACGTGATCCAAGG & \\
\hline
\end{tabular}

*Primer sequences derived from the S. pneumoniae R6 genome (Hoskins et al., 2001), as deposited in the TIGR Comprehensive Microbial Resource.

constant level in the nasopharynx, lungs and blood. The levels of both nanA and $\operatorname{sp} x B$ transcripts were higher in bacteria recovered from the nasopharynx than the lungs or blood. However, $p s a A$ did not show a consistent difference in expression between niches. The combined data from both in vivo experiments and two in vitro samples are also depicted as adjusted mRNA concentration, by comparing the CT values for each gene relative to that of 16S rRNA in the same sample (Fig. 2). The results indicate that the mRNA of $s p x B$ was the most abundant in vitro, followed by that of ply and cps2A, with nanA mRNA being the least abundant. In the nasopharynx, the mRNA of ply, followed

Table 2. Differential expression of virulence genes in various niches

Values shown are fold increase in mRNA concentration (mRNA concn $_{\text {niche } 1} / \mathrm{mRNA} \mathrm{concn}_{\text {niche } 2}$ ). Exp, experiment.

\begin{tabular}{|c|c|c|c|c|c|c|}
\hline \multirow[t]{2}{*}{ Gene } & \multicolumn{2}{|c|}{ Nose/lungs } & \multicolumn{2}{|c|}{ Nose/blood } & \multicolumn{2}{|c|}{ Lungs/blood } \\
\hline & $\operatorname{Exp} 1$ & $\operatorname{Exp} 2$ & $\operatorname{Exp} 1$ & $\operatorname{Exp} 2$ & Exp 1 & $\operatorname{Exp} 2$ \\
\hline $\operatorname{cbp} A$ & $1 \cdot 2$ & $3 \cdot 7$ & $2 \cdot 2$ & $6 \cdot 5$ & $1 \cdot 9$ & $1 \cdot 7$ \\
\hline pspA & $6 \cdot 5$ & $3 \cdot 8$ & $2 \cdot 0$ & $1 \cdot 5$ & $0 \cdot 3$ & $0 \cdot 4$ \\
\hline ply & $1 \cdot 3$ & $2 \cdot 8$ & $1 \cdot 8$ & $1 \cdot 8$ & $1 \cdot 4$ & $0 \cdot 7$ \\
\hline$p s a A$ & $2 \cdot 5$ & $0 \cdot 9$ & $2 \cdot 4$ & $0 \cdot 9$ & $1 \cdot 0$ & $1 \cdot 0$ \\
\hline $\operatorname{cps} 2 A$ & $0 \cdot 7$ & $0 \cdot 6$ & $1 \cdot 0$ & $1 \cdot 2$ & $1 \cdot 4$ & $1 \cdot 6$ \\
\hline piaA & $3 \cdot 1$ & $3 \cdot 1$ & $2 \cdot 3$ & $1 \cdot 8$ & $0 \cdot 7$ & $0 \cdot 6$ \\
\hline $\operatorname{nan} A$ & $22 \cdot 8$ & $15 \cdot 2$ & $56 \cdot 6$ & $9 \cdot 6$ & $2 \cdot 5$ & $0 \cdot 6$ \\
\hline $\operatorname{spxB}$ & $4 \cdot 3$ & $5 \cdot 6$ & $5 \cdot 5$ & $4 \cdot 1$ & $1 \cdot 3$ & $0 \cdot 7$ \\
\hline
\end{tabular}

by that of $c p s 2 A, p s p A$ and $p s a A$, was highly abundant relative to $16 \mathrm{~S}$ mRNA, whereas nanA mRNA was the least abundant. In the lungs, however, the mRNA of $c p s 2 A$ was the most abundant, followed by that of ply and psaA. Again, nanA mRNA was the least abundant. In the blood, the mRNAs of $c p s 2 A, p l y, p s p A$, $p s a A$ and piaA were present in high quantities, $c b p A$ mRNA was present at a lower level, while nanA mRNA was the least abundant.

\section{DISCUSSION}

Whilst for most individuals $S$. pneumoniae is carried asymptomatically in the nasopharynx, in susceptible hosts the pathogen can become invasive and cause diseases such as pneumonia, sepsis, meningitis and otitis media. The mechanisms of regulation of key virulence genes required for the survival and growth of the pneumococcus in the different niches that it occupies are poorly understood. Research in this area has been limited due to the inherent difficulties of isolating sufficient quantities of pure and intact bacterial RNA from infected host tissues. Recently, we developed an assay for relative quantitative RT-PCR analysis of total bacterial RNA isolated from the blood of mice at various times after intraperitoneal infection, and the levels of mRNA transcript for several virulence genes were measured. This permitted the first comparison of the relative kinetics of in vivo expression of proven pneumococcal virulence factors (Ogunniyi et al., 2002). As an extension of that work, we have now employed a novel, advanced, linear amplification procedure to amplify the low-yield RNA obtained from our in vivo model. This has enabled us to perform real-time 

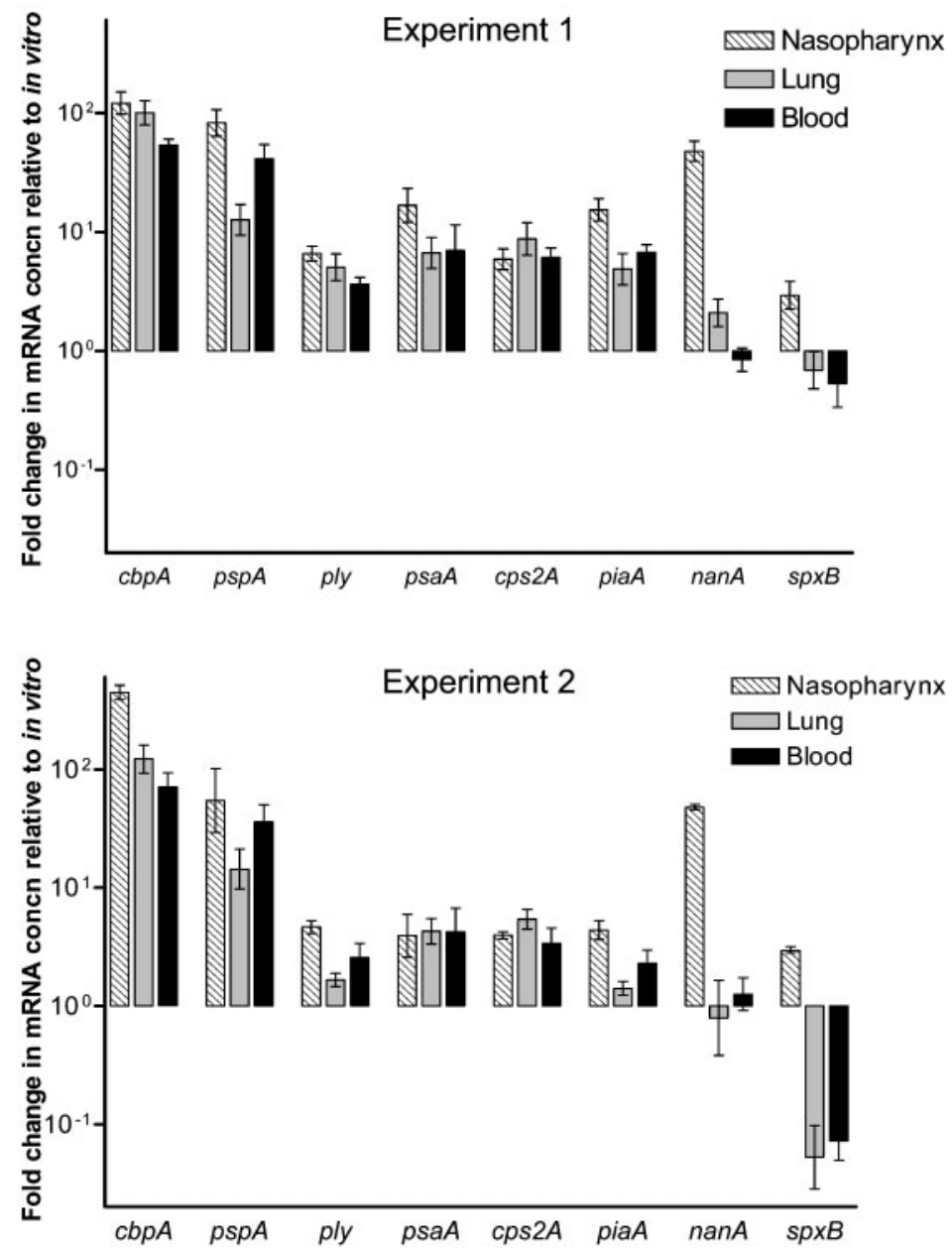

Fig. 1. Virulence gene mRNA concentrations in various in vivo niches, relative to concentrations in vitro. Real-time RT-PCR data for each gene were normalized against those obtained for the 16S rRNA control. Quantitative fold differences for each transcript were determined using the $2^{-\Delta \Delta C T}$ method described by Livak \& Schmittgen (2001). Data are means $\pm S D$ of triplicate reactions for each gene transcript. Data for two replicate experiments are presented separately.

RT-PCR on the samples recovered from the nasopharynx, lung and bloodstream of infected mice, thereby providing an insight into the behaviour of the pneumococcus at the transcriptional level in these distinct host niches.
In this study, we examined several pneumococcal virulence genes previously identified as being important in colonization and/or invasive disease. There was differential expression of $\operatorname{cbp} A, p s p A$, $p i a A, n a n A$ and $s p x B$ in the various

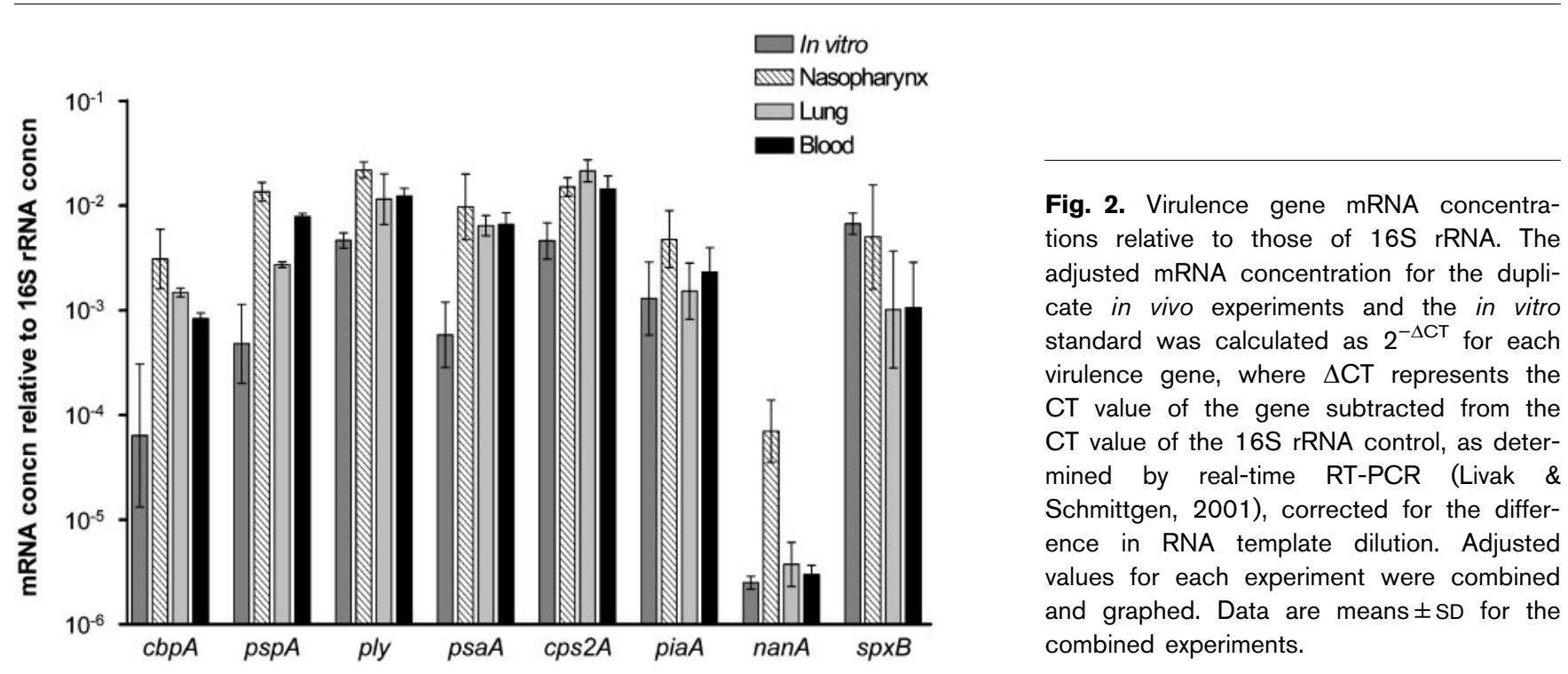


niches when compared to in vitro levels. However, the expression of $p l y, p s a A$ and $c p s 2 A$ in vivo did not appear to change significantly from the expression observed when grown in THY. CbpA, a highly conserved choline-binding protein, is thought to be important in mediating adherence to both the nasopharyngeal epithelium and activated lung epithelial and endothelial cells (Rosenow et al., 1997). In addition, in vitro interactions have been reported between $\mathrm{CbpA}$ and the human polymeric immunoglobulin receptor (hpIgR) present on nasopharyngeal epithelium (Zhang et al., 2000). A deficiency in CbpA has been shown to reduce the ability of mutant pneumococci to invade nasopharyngeal cells by over $90 \%$ compared to the parent strain, suggesting that pneumococci gain access to the interior of the cell by subversion of hpIgR. Data from the current study indicate that $c b p A$ mRNA is present at elevated levels in the nasopharynx and lungs compared to the bloodstream, consistent with the earlier findings. This finding is also consistent with a recent study (Orihuela et al., 2004a) that demonstrated that $\mathrm{CbpA}$ is not required for the entry of pneumococci into the bloodstream from the lungs, nor for survival in the blood. On another note, CbpA has also been shown to interact with factor $\mathrm{H}$ and C3 (Dave et al., 2001; Janulczyk et al., 2000), and to be important in a mouse sepsis model (Iannelli et al., 2004), suggesting a dual role for CbpA in colonization (adherence) and in systemic disease. This might explain why in this study, the expression of $\operatorname{cbp} A$ was also significantly upregulated in the lungs and blood, compared to expression in vitro.

Iron is essential for pneumococcal growth and survival, as it is for other pathogenic bacteria. PspA, another cholinebinding protein, has been shown to bind lactoferrin, an iron-sequestering glycoprotein, at respiratory mucosal sites. The binding of lactoferrin to pneumococci is believed to provide a way for the bacteria to interfere with host immune functions or to aid in the acquisition of iron at the site of infection (Hammerschmidt et al., 1999; Håkansson et al., 2001; Ren et al., 2003; Shaper et al., 2004). However, pneumococci producing a truncated form of PspA incapable of binding lactoferrin have been shown to successfully colonize the human nasopharynx (McCool et al., 2002). Therefore, the relative importance of lactoferrin binding by pneumococci is not certain. The results of our in vivo experiments suggest enhanced levels of $p s p A$ in the nasopharynx compared to the lungs, indicating that PspA is important for colonization of the nasopharynx. This study also demonstrated a higher level of pspA transcript in bacteria recovered from the blood of infected mice than from the lungs, consistent with the second function of PspA in preventing complement-mediated opsonization of bloodborne pneumococci (Tu et al., 1999; Ren et al., 2003). Similar results have been obtained by other groups using microarray analysis, which has shown that $p s p A$ transcription appears to be upregulated both in the blood and in Detroit cells (Orihuela et al., 2004b).

Another protein considered to be important in iron acquisition is PiaA, which is encoded on an iron-uptake ABC-transporter complex locus (Brown et al., 2001). Although the contribution of PiaA to pneumococcal virulence is not certain, immunization with PiaA has been shown to provide a similar degree of protection to PdB (pneumolysin toxoid) against systemic challenge with $S$. pneumoniae, and is therefore considered a potential vaccine candidate (Brown et al., 2001). We have shown that piaA mRNA is present at a higher level in the nasopharynx than in the other niches at $72 \mathrm{~h}$ following challenge. The level was approximately threefold greater in the nasopharynx than in the lungs, and approximately twofold greater in the nasopharynx than in the blood.

The expression of $p s a A$ was consistently high, but not significantly different among the niches examined in this study. PsaA is a metal-binding lipoprotein with specificity for $\mathrm{Mn}^{2+}$, and possibly also for $\mathrm{Zn}^{2+}$ (Dintilhac et al., 1997; Lawrence et al., 1998). It has also been shown that mutations in $p s a A$ have pleiotropic effects on various pneumococcal functions, including resistance to oxidative stress, adherence and virulence (Berry \& Paton, 1996; Claverys et al., 1999; Novak et al., 1998; Tseng et al., 2002; McAllister et al., 2004). In addition, immunization with PsaA has been found to confer significant levels of protection against nasopharyngeal carriage (Briles, 2000a, b; Palaniappan et al., 2005). The sustained expression of $p s a A$ in vivo is therefore consistent with an ongoing need to scavenge metal ions from the host, an essential requirement for virulence of pneumococci. This result is also in agreement with microarray data obtained by Orihuela et al. (2004b), which demonstrates that PsaA is upregulated to a similar extent in the blood of infected mice and in cultured Detroit-562 nasopharyngeal cells, compared to growth in $\mathrm{C}+\mathrm{Y}$ media.

Pneumolysin is an important virulence factor, contributing to multiple stages of the pathogenic process, and it is also involved in eliciting an immune response from the host. The cytotoxic characteristic of pneumolysin facilitates progression of disease by inhibiting ciliary beating in the human respiratory epithelium, thus augmenting the migration of bacteria to the lungs (Boulnois et al., 1991). It also acts by disrupting tight junctions between epithelial cells, which may provide an alternative pathway by which the pneumococcus infiltrates the bloodstream (Steinfort $e t$ al., 1989). Additionally, numerous studies have indicated that pneumolysin is important in the development of sepsis, with mutants lacking pneumolysin showing reduced replication and survival in the bloodstream of infected animals (Benton et al., 1995; Berry et al., 1999). The current study showed a higher level of ply mRNA in the nasopharynx than the blood, which was consistent between the two experiments conducted. This observation was interesting considering the importance of pneumolysin in sepsis, perhaps indicating that pneumolysin production is regulated at a posttranscriptional level, as suggested by Kwon et al. (2003). Alternatively, the production of pneumolysin may be regulated independently of environmental stimulus, with 
the niche influencing the release of the toxin rather than its transcription or translation.

Immunoelectron microscopy has been used elsewhere to show that transparent pneumococci, the phenotype commonly recovered from the lungs and nasopharynx, possess a significantly lower content of capsular polysaccharide than opaque bacteria, which predominate in the bloodstream (Kim et al., 1999). It was interesting to observe that there did not appear to be significant regulation of expression of the capsule locus, as determined by examining the relative levels of cps2A mRNA, suggesting that the pneumococcal capsule may be regulated at a post-transcriptional level. These results support previous work published from our laboratory that suggest that the level of encapsulation is determined by autophosphorylation of $\mathrm{CpsD}$, thereby allowing rapid assembly when the pathogen is exposed to a new environment, such as the bloodstream, in which the antiphagocytic properties of the capsule are highly desirable (Morona et al., 2000).

The expression of nanA was significantly elevated in the nasopharynx of infected mice compared to the other niches examined. NanA has been shown to have a role in facilitating bacterial adherence by removing terminal sialic acid residues from glycoconjugates. Additionally, NanA is able to desialylate the cell surface of Neisseria meningitidis and Haemophilus influenzae (Ram et al., 1998; Shakhnovich et al., 2002), as well as antibacterial components of human airway secretions (King et al., 2004), potentially reducing pneumococcal clearance whilst promoting the clearance of competing bacteria. Our results provide further support for an important role for NanA in colonization of the nasopharynx by pneumococci.

Pyruvate oxidase $(\mathrm{SpxB})$ is involved in the production of $\mathrm{H}_{2} \mathrm{O}_{2}$, which is proposed to have multiple roles in pathogenesis. $\mathrm{H}_{2} \mathrm{O}_{2}$ has been implicated in promoting carriage, as it has antimicrobial effects against competing bacteria in vitro, and has previously been shown to be expressed at higher levels in an oxygen- and $\mathrm{CO}_{2}$-rich environment (Pericone et al., 2000). In addition, the presence of $\mathrm{H}_{2} \mathrm{O}_{2}$ slows ciliary beating, thereby promoting pneumococcal progression to the lungs. This work indicated elevated levels of $s p x B$ in pneumococci harvested from the nasopharynx compared to samples recovered from the lungs and bloodstream, which is consistent with its putative roles in carriage and transition to the lungs.

In conclusion, we demonstrate the differential expression of several characterized pneumococcal virulence factors between colonizing and invading pneumococci during progression of disease. This is a new area of in vivo RNA research, not only in the pneumococcal field, but also in bacterial pathogenesis for many commensal organisms. The relative expression of these genes was found to support their putative roles in pathogenesis, and suggests which proteins might be more appropriate as vaccine antigens against nasal carriage or invasive pneumococcal disease.

\section{ACKNOWLEDGEMENTS}

This work was supported by Program grant 284214 from the National Health and Medical Research Council of Australia. K. S. L. is a recipient of a University of Adelaide Postgraduate Scholarship.

\section{REFERENCES}

Avery, O. T., MacLeod, C. M. \& McCarty, M. (1944). Studies on the chemical nature of the substance inducing transformation of pneumococcal types. Induction of transformation by a deoxyribonucleic acid fraction isolated from pneumococcus type III. J Exp Med 79, 137-158.

Benton, K. A., Everson, M. P. \& Briles, D. E. (1995). A pneumolysinnegative mutant of Streptococcus pneumoniae causes chronic bacteremia rather than acute sepsis in mice. Infect Immun 63, 448-455.

Berry, A. M. \& Paton, J. C. (1996). Sequence heterogeneity of PsaA, a 37-kilodalton putative adhesin essential for virulence of Streptococcus pneumoniae. Infect Immun 64, 5255-5262.

Berry, A. M., Ogunniyi, A. D., Miller, D. C. \& Paton, J. C. (1999). Comparative virulence of Streptococcus pneumoniae strains with insertion-duplication, point, and deletion mutations in the pneumolysin gene. Infect Immun 67, 981-985.

Boulnois, G. J., Paton, J. C., Mitchell, T. J. \& Andrew, P. W. (1991). Structure and function of pneumolysin, the multifunctional, thiolactivated toxin of Streptococcus pneumoniae. Mol Microbiol 5, 2611-2616

Briles, D. E., Hollingshead, S. K., King, J., Swift, A., Braun, P. A., Park, M. K., Ferguson, L. M., Nahm, M. H. \& Nabors, G. S. (2000a). Immunization of humans with recombinant pneumococcal surface protein A (rPspA) elicits antibodies that passively protect mice from fatal infection with Streptococcus pneumoniae bearing heterologous PspA. J Infect Dis 182, 1694-1701.

Briles, D. E., Hollingshead, S. K., Nabors, G. S., Paton, J. C. \& Brooks-Walter, A. (2000b). The potential for using protein vaccines to protect against otitis media caused by Streptococcus pneumoniae. Vaccine 8, S87-S95.

Brown, J. S., Ogunniyi, A. D., Woodrow, M. C., Holden, D. W. \& Paton, J. C. (2001). Immunization with components of two iron uptake ABC transporters protects mice against systemic Streptococcus pneumoniae infection. Infect Immun 69, 6702-6706.

Claverys, J. P., Granadel, C., Berry, A. M. \& Paton, J. C. (1999). Penicillin tolerance in Streptococcus pneumoniae, autolysis and the Psa ATP-binding cassette (ABC) manganese permease. Mol Microbiol 32, 881-883.

Dave, S., Brooks-Walter, A., Pangburn, M. K. \& McDaniel, L. S. (2001). PspC, a pneumococcal surface protein, binds human factor H. Infect Immun 69, 3435-3437.

Dintilhac, A., Alloing, G., Granadel, C. \& Claverys, J. P. (1997). Competence and virulence of Streptococcus pneumoniae: Adc and PsaA mutants exhibit a requirement for $\mathrm{Zn}$ and $\mathrm{Mn}$ resulting from inactivation of putative ABC metal permeases. Mol Microbiol 25, 727-739.

Håkansson, A., Roche, H., Mirza, S., McDaniel, L. S., Brooks-Walter, A. \& Briles, D. E. (2001). Characterization of binding of human lactoferrin to pneumococcal surface protein A. Infect Immun 69, 3372-3381.

Hammerschmidt, S., Bethe, G., Remane, P. H. \& Chhatwal, G. S. (1999). Identification of pneumococcal surface protein $A$ as a lactoferrin-binding protein of Streptococcus pneumoniae. Infect Immun 67, 1683-1687. 
Hoskins, J., Alborn, W. E., Jr, Arnold, J. \& 39 other authors (2001). Genome of the bacterium Streptococcus pneumoniae strain R6. J Bacteriol 183, 5709-5717.

lannelli, F., Chiavolini, D., Ricci, S., Oggioni, M. R. \& Pozzi, G. (2004). Pneumococcal surface protein $C$ contributes to sepsis caused by Streptococcus pneumoniae in mice. Infect Immun 72, 3077-3080.

Janulczyk, R., lannelli, F., Sjoholm, A. G., Pozzi, G. \& Bjorck, L. (2000). Hic, a novel surface protein of Streptococcus pneumoniae that interferes with complement function. J Biol Chem 275, 37257-37263.

Kim, J. O., Romero-Steiner, S., Sorensen, U. B., Blom, J., Carvalho, M., Barnard, S., Carlone, G. \& Weiser, J. N. (1999). Relationship between cell surface carbohydrates and intrastrain variation on opsonophagocytosis of Streptococcus pneumoniae. Infect Immun 67, 2327-2333.

King, S. J., Hippe, K. R., Gould, J. M., Bae, D., Peterson, S., Cline, R. T., Fasching, C., Janoff, E. N. \& Weiser, J. N. (2004). Phase variable desialylation of host proteins that bind to Streptococcus pneumoniae in vivo and protect the airway. Mol Microbiol 54, 159-171.

Kwon, H. Y., Kim, S. W., Choi, M. H., Ogunniyi, A. D., Paton, J. C. Park, S. H., Pyo, S. N. \& Rhee, D. K. (2003). Effect of heat shock and mutations in $\mathrm{ClpL}$ and $\mathrm{ClpP}$ on virulence gene expression in Streptococcus pneumoniae. Infect Immun 71, 3757-3765.

Lawrence, M. C., Pilling, P. A., Epa, V. C., Berry, A. M., Ogunniyi, A. D. \& Paton, J. C. (1998). The crystal structure of pneumococcal surface antigen PsaA reveals a metal-binding site and a novel structure for a putative ABC-type binding protein. Structure 6, 1553-1561.

Livak, K. J. \& Schmittgen, T. D. (2001). Analysis of relative gene expression data using real-time quantitative PCR and the $2^{-\Delta \Delta C T}$ method. Methods 25, 402-408.

McAllister, L. J., Tseng, H. J., Ogunniyi, A. D., Jennings, M. P., McEwan, A. G. \& Paton, J. C. (2004). Molecular analysis of the psa permease complex of Streptococcus pneumoniae. Mol Microbiol 53, 889-901.

McCool, T. L., Cate, T. R., Moy, G. \& Weiser, J. N. (2002). The immune response to pneumococcal proteins during experimental human carriage. J Exp Med 195, 359-365.

Morona, J. K., Paton, J. C., Miller, D. C. \& Morona, R. (2000) Tyrosine phosphorylation of $\mathrm{CpsD}$ negatively regulates capsular polysaccharide biosynthesis in Streptococcus pneumoniae. Mol Microbiol 35, 1431-1442.

Novak, R., Braun, J. S., Charpentier, E. \& Tuomanen, E. (1998). Penicillin tolerance genes of Streptococcus pneumoniae: the ABC-type manganese permease complex Psa. Mol Microbiol 29, 1285-1296.

Ogunniyi, A. D., Giammarinaro, P. \& Paton, J. C. (2002). The genes encoding virulence-associated proteins and the capsule of Streptococcus pneumoniae are upregulated and differentially expressed in vivo. Microbiology 148, 2045-2053.

Orihuela, C. J., Janssen, R., Robb, C. W., Watson, D. A. \& Niesel, D. W. (2000). Peritoneal culture alters Streptococcus pneumoniae protein profiles and virulence properties. Infect Immun 68, 6082-6086.

Orihuela, C. J., Gao, G., Francis, K. P., Yu, J. \& Tuomanen, E. I. (2004a). Tissue-specific contributions of pneumococcal virulence factors to pathogenesis. J Infect Dis 190, 1661-1669.
Orihuela, C. J., Radin, J. N., Sublett, J. E., Gao, G., Kaushal, D. \& Tuomanen, E. I. (2004b). Microarray analysis of pneumococcal gene expression during invasive disease. Infect Immun 72, 5582-5596.

Palaniappan, R., Singh, S., Singh, U. P. \& 7 other authors (2005). Differential PsaA-, PspA-, PspC-, and PdB-specific immune responses in a mouse model of pneumococcal carriage. Infect Immun 73, 1006-1013.

Paton, J. C. (1998). Novel pneumococcal surface proteins: role in virulence and vaccine potential. Trends Microbiol 6, 85-87.

Pericone, C. D., Overweg, K., Hermans, P. W. \& Weiser, J. N. (2000). Inhibitory and bactericidal effects of hydrogen peroxide production by Streptococcus pneumoniae on other inhabitants of the upper respiratory tract. Infect Immun 68, 3990-3997.

Ram, S., Sharma, A. K., Simpson, S. D., Gulati, S., McQuillen, D. P., Pangburn, M. K. \& Rice, P. A. (1998). A novel sialic acid binding site on factor $\mathrm{H}$ mediates serum resistance of sialylated Neisseria gonorrhoeae. J Exp Med 187, 743-752.

Ren, B., Szalai, A. J., Thomas, O., Hollingshead, S. K. \& Briles, D. E. (2003). Both family 1 and family 2 PspA proteins can inhibit complement deposition and confer virulence to a capsular serotype 3 strain of Streptococcus pneumoniae. Infect Immun 71, 75-85.

Rosenow, C., Ryan, P., Weiser, J. N., Johnson, S., Fontan, P., Ortqvist, A. \& Masure, H. R. (1997). Contribution of novel cholinebinding proteins to adherence, colonization and immunogenicity of Streptococcus pneumoniae. Mol Microbiol 25, 819-829.

Shakhnovich, E. A., King, S. J. \& Weiser, J. N. (2002). Neuraminidase expressed by Streptococcus pneumoniae desialylates the lipopolysaccharide of Neisseria meningitidis and Haemophilus influenzae: a paradigm for interbacterial competition among pathogens of the human respiratory tract. Infect Immun 70, 7161-7164.

Shaper, M., Hollingshead, S. K., Benjamin, W. H. J. \& Briles, D. E. (2004). PspA protects Streptococcus pneumoniae from killing by apolactoferrin, and antibody to PspA enhances killing of pneumococci by apolactoferrin. Infect Immun 72, 5031-5040.

Steinfort, C., Wilson, R. \& Mitchell, T. (1989). Effects of Streptococcus pneumoniae on human respiratory epithelium in vitro. Infect Immun 57, 2006-2013.

Tseng, H. J., McEwan, A. G., Paton, J. C. \& Jennings, M. P. (2002). Virulence of Streptococcus pneumoniae: PsaA mutants are hypersensitive to oxidative stress. Infect Immun 70, 1635-1639.

Tu, A. H., Fulgham, R. L., McCrory, M. A., Briles, D. E. \& Szalai, A. J. (1999). Pneumococcal surface protein A inhibits complement activation by Streptococcus pneumoniae. Infect Immun 67, 4720-4724.

Wu, H.-Y., Virolainen, A., Mathews, B., King, J., Russell, M. W. \& Briles, D. E. (1997). Establishment of a Streptococcus pneumoniae nasopharyngeal colonization model in adult mice. Microb Pathog 23, 127-137.

Zhang, J.-R., Mostov, K. E., Lamm, M. E., Nanno, M., Shimida, S., Ohwaki, M. \& Tuomanen, E. I. (2000). The polymeric immunoglobulin receptor translocates pneumococci across human nasopharyngeal epithelial cells. Cell 102, 827-837. 